\title{
Synthesis and antihyperlipidaemic activity of a new piperine derivative
}

\author{
Mungunnaran Damdindorj ${ }^{1,2,3}$, Gereltu Borjihan², Odontuya Gendaram³, \\ Bayarmaa Bold ${ }^{4 *}$ \\ ${ }^{1}$ Graduate school, Mongolian University of Life Sciences, Ulaanbaatar, 17024, Mongolia \\ ${ }^{2}$ Institute of Mongolian Medicine Chemistry, Inner Mongolia University, 235 Da Xue West Road, \\ Hohhot, 010020, P.R. China \\ ${ }^{3}$ Institute of Chemistry and Chemical Technology, Mongolian Academy of Sciences, Ulaanbaatar, 13330, Mongolia \\ ${ }^{4}$ Research and Innovation office, Mongolian University of Life Sciences, Ulaanbaatar, 17024, Mongolia
}

*Corresponding author: E-mail: bayarmaa_iao@muls.edu.mn ; ORCID:0000-0002-6797-821X

Received: 08 October 2021; revised: 12 December 2021; accepted: 13 December 2021

\begin{abstract}
Long pepper (Piper longum Linn.) is widely used as a medicinal substance in traditional Ayurvedic medicine. Its major alkaloid piperine is the main active constituent with various therapeutic activities and has low solubility in water. In this study, a soluble new derivative of a piperine alkaloid, named N-leucinylpiperamide was synthesized. The animal experiment showed that N-leucinylpiperamide has more hypolipidemic effects than commercially available simvastatin and piperine in modulating serum lipids in Wistar male rats. At the amount of $10 \mathrm{mg} / \mathrm{kg} \mathrm{bw}$, it significantly reduced TC $(-52.4 \%)$, TG $(-61.7 \%)$, and LDL-C (-27.8\%), respectively, and increased HDL-C (+147.4\%) in the serum of the high-lipid model group. Furthermore, the synthesized N-leucinylpiperamide had no noticeable cytotoxicity against HepG2 cell line in vitro. Thus, our study shows that $\mathrm{N}$-leucinylpiperamide has an ability to improve serum lipid profile in hyperlipidemic model rats and could be a valuable promising agent for the preventing hyperlipidemia.
\end{abstract}

Keywords: Piperine, alkaloid, cholesterol, hyperlipidemia, amino acid, solubility

\section{INTRODUCTION}

The Piper species have a long history as a condiment in many countries, but they have been more valued for their therapeutic properties and broadly used in Ayurvedic medicine. The plant contains many alkaloids, such as piperine, chavicin, and piperamine; the most abundant of which is piperine, $4-5 \%[1,2]$.

Piperine alkaloid is a non-soluble piperic acid amide, predominantly found in Piper longum L. (long pepper) and Piper nigrum L. (black pepper) of the Piperaceae family. Its content is 3-5 percent on a dry weight basis $[3,4]$. By systematic pharmacological studies, piperine showed having diverse pharmacological activities [5]. As a bio-active component, it has the potency to reduce blood cholesterol and triglycerides [6, 7]. In addition, it reduces low-density lipoprotein, very lowdensity lipoprotein, and 3-hydroxy-3-methylglutaryl coenzyme A (HMG-CoA) reductase activity in the tissues, while increases lipoprotein lipase (LPL) and lecithin:cholesterol acyltransferase (LCAT) [8] as well possesses hypolipidemic activity in diet-induced experimental hyperlipidemic rats [9]. Thus, piperine and its derivatives may significantly modulate lipid parameters and lead the compound to develop new potential antihyperlipidemic drug candidates.

However, its biological applications are denied due to its low aqueous solubility [6, 10], which is a significant barrier to drug development. Therefore, one main concern is the development of the formulations to increase its solubility $[11,12]$.

Many studies have shown that improving the solubility of piperine affects its bioavailability and increases pharmacological activity [10]. Introduction of amino acids is one way to increase the water solubility of non-soluble compounds. Amino acids are widely used as carriers of poorly absorbed therapeutic agents via increasing their water solubility [13].

By the research on piperine as an inhibitor of Leishmania, the combination of piperonic acid, which is a piperine hydrolyzed product, and amino acid methyl esters showed better anti-Leishmanial activity than natural piperine alkaloid [14].

Thus, we hypothesised that such a combination of naturally occurring piperine and amino acid ester 
might possess more anti-hypolipidemic effects and low cytotoxicity. In this study, we report synthesis and evaluation of the antidyslipidemic activity of a new form of piperine, $\mathrm{N}$-leucinylpiperamide.

\section{EXPERIMENTAL}

Chemical reagents: The Piper longum $\mathrm{L}$. fruits were purchased from Yikan Chinese Herbal Medicine Ltd. and Hainan Zun Ao Technology Development Co. Ltd., China, respectively. The specimen was identified according the method accepted previously [15]. Piperic acid was prepared at the Institute of Mongolian Medicine Chemistry, Inner Mongolia University with a purity rate $>98 \%$. The commercially available simvastatin was provided by Hai Zheng Pharmaceutical Co. Ltd, China. The kits for determining the total cholesterol (TC), triglyceride (TG), low-density lipoprotein cholesterol (LDL-C), and high-density lipoprotein cholesterol (HDL-C) were supplied by the BioSino Bio-Technology and Science Inc., China. All other chemicals were analytical grade from Sigma-Aldrich.

Equipment: Ultra-performance liquid chromatography (UPLC), Waters acquity UPLC, PDA detector, USA with a mobile phase of acetonitrile-water was used for the determination of the purity of synthesized compounds. ${ }^{1} \mathrm{H}$ NMR and ${ }^{13} \mathrm{C}$ NMR spectra were recorded on a Bruker AV $500 \mathrm{MHz}$ nuclear magnetic resonance (NMR) spectrometer at $25^{\circ} \mathrm{C}$. Mass spectrometry (MS) analysis was performed on LCQ ADVANTAGE MAX Mass Spectrometer System. Serum lipid profile was measured by commercial kit with a Pronto Evolution Biochemistry Analyser, Italy.

Cell culture: HepG2 cells obtained from the Chinese Academy of Sciences Cell Bank were cultured in DMEM supplemented with $10 \%$ heat-inactivated fetal bovine serum (FCS, HyClone, Utah, USA), 4 mM/L L-glutamine, $100 \mathrm{U} / \mathrm{mL}$ penicillin, and $100 \mu \mathrm{g} / \mathrm{mL}$ streptomycin under a humidified atmosphere of $5 \% \mathrm{CO}_{2}$ and $95 \%$ air at $37^{\circ} \mathrm{C}$. When reaching $80 \%$ confluence, the medium was discarded; the cells were washed 3 times with phosphatebuffered saline (PBS) and digested with $0.25 \%$ trypsin. The cells were re-suspended in DMEM, containing 10\% fetal bovine serum (FBS), and centrifuged at $1000 \mathrm{rpm}$ for $5 \mathrm{~min}$. The supernatant was discarded and a proper amount of DMEM containing 10\% FBS was added into the cells to prepare a fine suspension. Cell number was counted and seeded into the 96-well plates at a density of $1 \times 10^{4} / \mathrm{ml}, 100 \mu \mathrm{L}$ per well, and cultured at $37^{\circ} \mathrm{C}$ with $5 \% \mathrm{CO}_{2}$ and saturated humidity for $24 \mathrm{~h}$.

Animals: Animal experiments were carried out with 50 male adult Wistar rats with the weight of $190 \pm 10$ $\mathrm{g}$, provided by the Research Center for Laboratory Animals Science, China. According to the Institutional Guidelines for the Care and Use of Laboratory Animals, all procedures were performed following the ethical standards, after approval from the Institutional Animal Care and Use Committee (Inner Mongolia University, China).
After initial acclimatization for a week, animals were randomly divided into five different groups as described in the experimental design. The rats were housed in plastic cages under the controlled conditions of the ambient temperature of $24 \pm 0.5^{\circ} \mathrm{C}$ and $40-70 \%$ relative humidity with a $12 \mathrm{~h}$ light/dark cycle for 15 days. For the experiment, rats were fed with either a normal or freshly prepared high-fat diet ( $15 \mathrm{~g} / \mathrm{rat} / \mathrm{d})$ or water ad libitum.

Chemistry of $\mathrm{N}$-leucinylpiperamide: Extraction of piperine from Piper longum $\mathrm{L}$. fruits and the following synthesis of piperic acid were carried out according to literature methods described $[16,17]$. Then, the synthesized piperic acid $(0.218 \mathrm{~g})$ and L-leucine methyl ester $(0.181 \mathrm{~g})$ were dissolved in $3 \mathrm{~mL}$ anhydrous dimethylformamide (DMF) in a dry three-necked flask equipped with a reflux condenser and connected to the line of $\mathrm{N}_{2}$ gas. The solution was placed in the ice bath for 30-60 min for instant cooling and 0.221 $\mathrm{g}$ of phosphonium hexafluorophosphate (BOP) was added. Then, $0.5 \mathrm{~mL}$ of $\mathrm{N}, \mathrm{N}$-diisopropylethylamine (DIEA) was added to the mixture slowly stirring at room temperature for $24 \mathrm{~h}$. After that DMF was removed by evaporation, a viscous solid was dissolved in ethyl acetate $(150 \mathrm{~mL})$. Subsequently, the solution was washed with saturated sodium chloride $(\mathrm{NaCl})$ solution, $5 \%$ citric acid, $5 \% \mathrm{NaOH}$, and then twice by distilled water in a separatory funnel. Afterward, ethyl acetate was removed by evaporating and the water was freezedried, subsequently a yellow solid was obtained $(0.191$ g). The solid was dissolved in methanol $(10 \mathrm{~mL})$ and sodium methoxide (10x) was added afterward. Then, it was stirred at room temperature for $24 \mathrm{~h}$, and methanol was removed through evaporation. The mixture was dissolved in $60 \mathrm{~mL}$ of $5 \%$ sodium bicarbonate $\left(\mathrm{NaHCO}_{3}\right)$ solution followed by the extraction with methylene chloride $\left(\mathrm{CH}_{2} \mathrm{Cl}_{2}\right) 3$ times. After all, the reaction mixture was poured into $200 \mathrm{~mL}$ of $30 \% \mathrm{HCl}$ to produce a yellow precipitate and was recrystallized to give $0.153 \mathrm{~g}$ of a new compound, N-leucinylpiperamide.

Experimental design: To test the anti-hyperlipidemic activities, the rats were divided into the following groups:

Group I - Normal diet control;

Group II - High-fat diet control;

Group III - High-fat diet + simvastatin (10 mg/kg bw);

Group IV - High-fat diet + piperine (10 mg/kg bw);

Group V - High-fat diet + N-leucinylpiperamide

(10 mg/kg bw);

The normal diet group (I) was fed with a standardized laboratory chow diet, containing the standard composition of necessary macro- and micronutrients ( $56 \%$ carbohydrate, $18.5 \%$ protein, $8 \%$ fat, $12 \%$ fiber, and adequate levels of minerals and vitamins). While others were fed with high-fat diet recipe with the following nutrition: cholesterol $(3 \%)$, sodium cholate $(0.5 \%)$, lard $(10 \%)$, wheat flour $(17.3 \%)$, millet $(8.65 \%)$, vitamins $(0.0865 \%)$, salt $(0.7785 \%)$, bran $(21.685 \%)$, fish $(1.73 \%)$, bone meal $(1.73 \%)$ and beans material 
$(17.3 \%)$ to provide hyperlipidemic model.

Treatment groups (III, IV, and V) were given a daily oral administration of each compound sample $(4 \mathrm{~mL} / \mathrm{kg})$ for 14 days, which were prepared as a suspension of sodium carboxymethyl cellulose $(0.5 \%$ in water).

Biochemical analyses: The body weights were measured daily and the daily food intake was recorded. After 14 days of oral administration of treatments, the animals have fasted for $12 \mathrm{~h}$. The blood samples were collected and centrifuged at $3000 \mathrm{rpm}$ for 15 minutes at $10^{\circ} \mathrm{C}$ to obtain serum. Freshly prepared serum samples were frozen at $-80^{\circ} \mathrm{C}$ until biochemical analyses.

Serum TC, TG, LDL-C, and HDL-C were determined with a biochemistry analyzer using standard kits.

In vitro cytotoxicity: For performing the MTT cell viability assay, the medium was replaced with fresh media, containing various concentrations of each compound $(0.5,1.0,2.0,4.0,6.0$, and $8.0 \mu \mathrm{M})$ prepared in DMSO. After $24 \mathrm{~h}$ incubation, $50 \mu \mathrm{L}$ of MTT (3-(4,5-dimethylthiazol-2-yl)2,5-diphenyl tetrazolium bromide) reagent was added into each well and incubated at $37{ }^{\circ} \mathrm{C}$ for $4 \mathrm{~h}$. After that medium was discarded and $1 \mathrm{~mL}$ of DMSO was added to dissolve the formazan crystals. The plates were gently shaken and absorbance at $490 \mathrm{~nm}$ was obtained in the microplate reader. In the blank control and the untreated wells, cell viability was $100 \%$.

Statistical analysis: All results are expressed as the mean \pm SD of animals in each group. Statistical analyses are conducted using Student's t-test [2]. Significance levels at $p<0.05$ and 0.001 were considered to indicate statistical significance.

\section{RESULTS AND DISCUSSION}

A piperine-amino acid new derivative, $\mathrm{N}$-leucinylpiperamide was prepared with the synthetic route as illustrated in Fig. 1.

As described, in the first step, piperine (1) was hydrolyzed giving a piperic acid, which is an efficient and cheap way for the preparation of piperic acid (3) with a yield of $86.6 \%$. In the second step, piperic acid was reacted with L-leucine methyl ester to afford $\mathrm{N}$-leucinyl methyl ester piperamide ( $\mathrm{N}$-leucinylpiperamide methyl ester, 4). Here, carboxylic group of piperic acid (3) is the main site to link with amino acid ester via amide bond formation. In the third step, the N-leucinylpiperamide methyl ester is the critical intermediate product to obtain the final expected product, $\mathrm{N}$-leucinylpiperamide (5) with a yield of $80.1 \%$

The purity of synthesized $\mathrm{N}$-leucinylpiperamide was assessed by using UPLC with a mobile phase of acetonitrile:water, 75:35. In addition, the structure of $\mathrm{N}$-leucinylpiperamide was determined using mass spectrometry and ${ }^{1} \mathrm{H}$ and ${ }^{13} \mathrm{C}$ nuclear magnetic resonance (NMR).

A new derivative of piperine alkaloid, N-leucinylpiperamide, was tested in male Wistar rats. Male rats were chosen in order to avoid the estrogen effects on lipid metabolism [18].

During the experiment, four critical biomarkers of hyperlipidemia showed an indicative change: the levels of total cholesterol (TC), triglyceride (TG), low-density lipoprotein cholesterol (LDL-C) were significantly increased, while the level of high-density lipoprotein cholesterol (HDL-C) was decreased in serum of the model male rats. Herein, the anti-hyperlipidemic activities of samples were expressed as the differences of lipid parameters TC, TG, LDL-C, and HDL-C in the rat serum of experimental and control groups.

Results showed that the lipid-lowering activity of $\mathrm{N}$-leucinylpiperamide was comparable to piperine and simvastatin (Table 1).

In an animal experiment, the new derivative $\mathrm{N}$-leucinylpiperamide showed noticeable hypolipidemic effects on hyperlipidemia in rats, showing a substantial activity in modulating serum lipids in Wistar rats. At the dose of $10 \mathrm{mg} / \mathrm{kg} \mathrm{bw}$, it significantly reduced TC $(-52.4 \%)$, TG (-61.7\%), and LDL-C (-27.8\%), respectively, and increased HDL-C $(+147.4 \%)$ in the serum of the hyperlipidemic model animals. Consistent with<smiles>O=C(O)/C=C/C=C/c1ccc2c(c1)OC([18O]CCO)O2</smiles><smiles>O=C(O)/C=C/C=C/c1ccc2c(c1)OCO2</smiles>

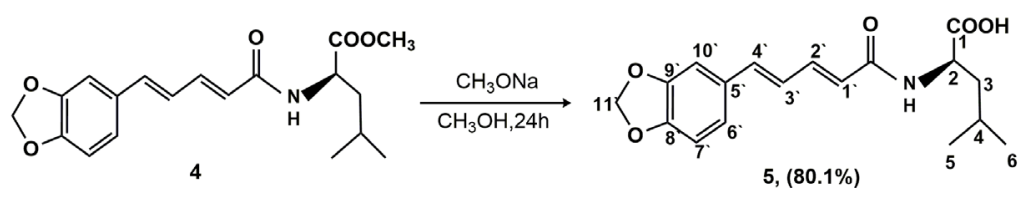

Fig. 1. Synthetic route of $\mathrm{N}$-leucinylpiperamide synthesis 
Table 1. Effect of antihyperlipidemic compounds on serum lipid content

\begin{tabular}{llcccc}
\hline & \multirow{2}{*}{ Groups $^{\mathrm{a}}$} & \multicolumn{4}{c}{ Serum lipid profile $^{\mathrm{b}}, \mathrm{mM}$} \\
& & TC & TG & LDL-C & HDL-C \\
\hline I & Control & $1.46 \pm 0.51$ & $0.67 \pm 0.26$ & $2.39 \pm 1.64$ & $0.30 \pm 0.10$ \\
II & HFD model & $9.41 \pm 1.97$ & $2.27 \pm 2.10$ & $3.99 \pm 0.62$ & $0.19 \pm 0.05$ \\
III & Simvastatin & $7.06 \pm 1.74$ & $1.01 \pm 0.54$ & $3.34 \pm 1.04$ & $0.23 \pm 0.04$ \\
IV & Piperine & $7.32 \pm 1.31$ & $0.70 \pm 0.12$ & $3.47 \pm 0.63$ & $0.26 \pm 0.02$ \\
V & N-leucinylpiperamide & $4.48 \pm 1.24$ & $0.87 \pm 0.13$ & $2.88 \pm 1.24$ & $0.47 \pm 0.31$ \\
\hline
\end{tabular}

a Fifty Wistar rats were divided into 5 groups and were subject to serum lipid content measurement after treatment as described in the Experimental section.

b Values are the mean of SD of 10 rats.

other literature values $[9,17]$, these results indicate a significant difference between the serum parameters of the treatment group and the control group. In addition, these results suggest that the development of hyperlipidemia in experimental animals was successful showing its reliability.

In our study, commercially available simvastatin was chosen to compare the antihyperlipidemic activity. Simvastatin reduced the corresponding TC, TG, and LDL-C lipid profiles by $25.0 \%, 55.5 \%$, and $16.3 \%$, respectively, and increased the HDL-C level by $21 \%$ up at the same amount as the $\mathrm{N}$-leucinylpiperamide. Simvastatin, lovastatin, and pravastatin are the main members of the statin drug class widely used to reduce lipids in the blood [19, 20]. However, as reported, these drugs have unfavourable side effects, like severe myopathy, memory loss [21], and liver damage [22].

Piperine given at the same dose reduced the TC, TG, and LDL in serum levels by $22 \%, 61.2 \%$, and $13.0 \%$, respectively. Then, the serum HDL level was increased by $36.84 \%$ in the group of treated with piperine.

In comparison, the lipid-lowering activity of $\mathrm{N}$-leucinylpiperamide with simvastatin, the level of serum TC, TG, and LDL-C was decreased by $52 \%, 10 \%$, and $42 \%$, respectively, and increased the serum HDL-C level by $86 \%$ than simvastatin in the hyperlipidemic model animals.

Relevant studies have shown that the piperlongiminine from the $P$. longum extract decreased the TC and TG by 1.5-2.5 times, LDL-C by 1.3-1.5 times, while increased HDL-C by $1.9-3$ times after oral administration at a dose of $10 \mathrm{mg} / \mathrm{kg}$ in high-fat diet rats for 14 days [2,9]. In our study, the hyperlipidemic model group had a significant reduction in the fat profile compared to the control group, in particular, N-leucinylpiperamide reduced TC in the plasma of rats by 1.5 times, TG and LDL-C by 1.2 times. The amount of HDL-C was increased by 2 times, resulting in the synthesis of a highly active functional compound of $\mathrm{N}$-leucinylpiperamide against hyperlipidemia.

As a result, N-leucinylpiperamide significantly modulated lipid parameters in animal blood and its effect was markedly higher than piperine and simvastatin.

A major concern in developing novel drugs from plants is toxicity level. Based on the study, the literature has shown that the piperine may cause liver toxicity in CF-1 albino mice via an increase of serum alanine aminotransferase (ALT), serum aspartate aminotransferase (ASAT), and alkaline phosphatase (ALP) [23]. Another study on determining the $\mathrm{LD}_{50}$ values for a single intraperitoneal (IP), intravenous (IV), intramuscular (IM), intragastric (IG), and subcutaneous (SC) administration of piperine to adult male mice showed that piperine is acutely toxic to mice, rats and hamsters [24].

In our study, cytotoxicity of all tested compounds was investigated against HepG2 cell line at concentrations, ranging from $0.5-8 \mu \mathrm{M}$. The HepG2 cells were chosen as a suitable model to study cellular cholesterol homeostasis due to their high degree of morphological and functional differentiation in vitro [23, 25]. All substances were evaluated in three independent experiments, in triplicate. Results are shown in Table 2. Cell viability decreased with the increase in

Table 2. Effect of antihyperlipidemic compounds on cell cytotoxicity

\begin{tabular}{lllllll}
\hline \multirow{2}{*}{ Groups $^{\mathrm{a}}$} & \multicolumn{6}{c}{ Cell viability (\%) at various concentrations, $\mathrm{mM}$} \\
\cline { 2 - 7 } & 0.5 & 1 & 2 & 4 & 6 & 8 \\
\hline III Simvastatin & 79.03 & 66.74 & 55.71 & 46.15 & 31.68 & 28.07 \\
IV Piperine & 89.02 & 79.47 & 67.78 & 56.26 & 48.68 & 41.92 \\
V $\begin{array}{l}\text { N-leucinyl- } \\
\text { piperamide }\end{array}$ & 92.53 & 83.61 & 72.64 & 63.44 & 54.21 & 49.43 \\
\hline
\end{tabular}

a HepG2 cells were divided into 3 groups and were subject to treatment with compounds as described in the Experimental section.

${ }^{b}$ Values are the average of at least three tests.

concentrations of compounds. The $\mathrm{IC}_{50}$ of N-leucinylpiperamide was evaluated according to its concentration and cell viability. Results of experiments exhibited that the $\mathrm{IC}_{50}$ values of $\mathrm{N}$-leucinylpiperamide, piperine, and simvastatin were $7.7 \mu \mathrm{M}, 5.6 \mu \mathrm{M}$, and $3.2 \mu \mathrm{M}$, respectively, indicating that the cell viability in all testing concentrations of $\mathrm{N}$-leucinylpiperamide was higher than the others. The $\mathrm{IC}_{50}$ values for compounds that inhibit cell viability by more than $50 \%$ are plotted graphically from the concentration-effect curve, shown in Fig. 2. The results showed that N-leucinylpiperamide reduced cell viability of HepG2 by $50.57 \%$, while 


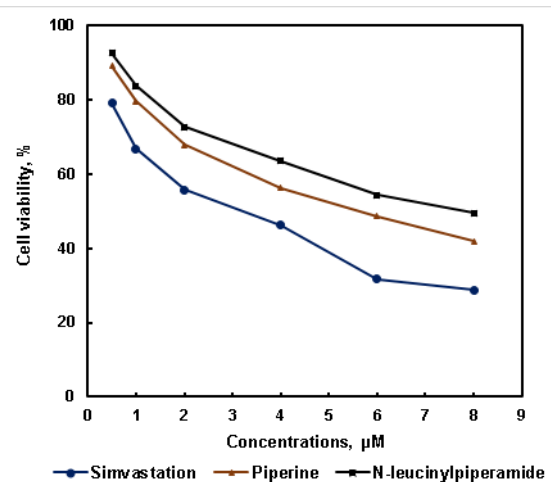

Fig. 2. The $I_{50}$ values of antihyperlipidemic compounds with various concentrations on the cell viability

simvastatin and piperin inhibited the cell growth by $71.93 \%$ and $62.9 \%$, respectively, at the same dose. In particular, N-leucinylpiperamide showed twice-lower cytotoxicity to the cell line than the simvastatin at the 8 $\mu \mathrm{M}$ concentration.

Piperine, as an alkaloid with poor solubility, requires modifications for its increased pharmaceutical activities $[10,11]$. The structure of piperine is suitable for chemical modifications; therefore, it can present an advantage in developing novel derivatives with various therapeutic activities [26]. Accordingly, several research studies were conducted to alter piperine to be effective to deliver in a targeted manner, such as fabricated nanoliposomal complex of piperine and an anti-CD133 monoclonal antibody [27], piperine-loaded mono-disperse chitosan nanoparticles [28] as well as a self-emulsifying drug delivery system of piperine to enhance its solubility and bioavailability [11].

While, introduction of amino acids to parent drugs is the one way to overcome the limited therapeutic applications of non-soluble drug compounds [29, 30]. Accordingly, formulating piperine with L-leucine methyl ester improved the solubility, bioavailability, and thereby its therapeutic activity of piperine.

\section{CONCLUSIONS}

In this work, piperine-amino acid derivative, $\mathrm{N}$-leucinylpiperamide, was synthesized using L-leucine methyl ester, and results indicate that $\mathrm{N}$-leucinylpiperamide possesses a higher lipid-lowering activity over its parent compound piperine and simvastatin in highfat diet model animals. Such behaviour is attributed to the formation with L-leucine methyl ester since the application of amino acids in the structural modification of natural products can improve many properties, including solubility and bioavailability of therapeutic drugs. Therefore, this finding suggests the application of amino acid ester could be a potential system to oral delivery of piperine and newly synthesized $\mathrm{N}$-leucinylpiperamide could be a valuable promising anti-hyperlipidemic candidate.

\section{ACKNOWLEDGEMENTS}

This study was carried out as a part of research supported by the Natural Sciences Foundation of Inner Mongolia (2011), the Importance Project of Science and Technology of China (2009ZX0913-103).

\section{REFERENCES}

1. Kumar S., Kamboj J., Suman, Sharma S. (2011) Overview for various aspects of the health benefits of Piper Longum Linn. fruit. J. Acupunct. Meridian Stud., 4(2),134-140. $\quad$ https://doi.org/10.1016/ S2005-2901(11)60020-4

2. Erdenebaatar S., Borjihan G., Zhaorigetu S. (2013) The preparation and antihyperlipidaemic assay of piperlonguminine in vivo. Phytochemistry Letters, 6(1), 101-105. https://doi.org/10.1016/j. phytol.2012.12.002

3. Zaveri M., Khandhar A., Patel S., Patel A. (2010) Chemistry and pharmacology of Piper longum L. Int. J. Pharm. Sci. Rev. Res., 5(1), 67-76.

4. Tiwari A., Mahadik R., Gabhe G. (2020) Piperine: A comprehensive review of methods of isolation, purification, and biological properties. Medicine in Drug Discovery, 7(100027). https://doi. org/10.1016/j.medidd.2020.100027

5. Lee E.B., Shin K.H., Woo W.S. (1984) Pharmacological study on piperine. Archives of Pharmacal Research, 7, 127-132. https://doi. org/10.1007/BF02856625

6. Gorgani L., Mohammadi M., Najafpour D., Nikzad M. (2017) Piperine-the bioactive compound of blackpepper: from isolation to medicinal formulations. Comprehensive Reviews in Food Science and Food Safety, 16(1), 124-140. https:// doi.org/10.1111/1541-4337.12246

7. Vijayakumar S., Nalini N. (2006) Lipid-lowering efficacy of piperine from Piper nigrum L. in high-fat diet and antithyroid drug-induced hypercholesterolemic rats. J. Food Biochem., 30(4), 405-421.

8. Stojanović-Radić Z., Pejčić M., Dimitrijević M., Aleksić A., Anil Kumar N.V., et al. (2019) Piperine-A major principle of Black pepper: A review of its bioactivity and studies. Applied Sciences, 9(20), 4270-4299. https://doi.org/10.3390/app9204270

9. Bao L., Bai Sh., and Borjihan G. (2012) Hypolipidemic effects of a new piperine derivative GB-N from Piper longum in high-fat diet-fed rats. Pharmaceutical Biology, 50(8), 962-967. https:// doi.org/10.3109/13880209.2012.654395

10. Stasiłowicz A., Rosiak N., Tykarska E., Kozak M., Jenczyk J., et al. (2021) Combinations of piperine with hydroxypropyl- $\beta$ cyclodextrin as a multifunctional system. Int. J. Mol. Sci., 22, 4195. https://doi.org/10.3390/ijms22084195

11. Shao B., Cui C., Ji H., Tang J., Wang Z., et al. (2014) Enhanced oral bioavailability of piperine by self-emulsifying drug delivery systems: in vitro, 
in vivo and in situ intestinal permeability studies. Drug Delivery, 22(6), 740-747. https://doi.org/10.3 109/10717544.2014.898109

12. Wu Z., Xia X., Huang X. (2012) Determination of equilibrium solubility and apparent oil/water partition coefficient of piperine. J. Jinan Univ., 33, 473-476

13. Vale N., Ferreira A., Matos J., Fresco P., Gouveia M.J. (2018). Amino acids in the development of prodrugs. Molecules, 23(9), 2318. https://doi. org/10.3390/molecules23092318

14. Singh I.P., Jain S.K., Kaur A., Singh S., Kumar R., et al. (2010) Synthesis and antileishmanial activity of piperoyl-amino acid conjugates. Eur. J. Med. Chem., 45(8), 3439-45. https://doi.org/10.1016/j. ejmech.2010.04.033

15. Committee of Chinese Pharmacopoeia. Pharmacopoeia of P.R.C. First Part. Chemical Industry Press, Beijing, 188.

16. Han J., Borjihan G., Bai R., Sun Z., Bao N., et al. (2008) Synthesis and anti-hyperlipidemic activity of a novel starch piperinic ester. Carbohydrate Polymers, 71(3), 441-447. https://doi.org/10.1016/j. carbpol.2007.06.014

17. Jin Z., Borjihan G., Zhao R., Sun Z., Bao N., et al. (2009) Antihyperlipidemic compounds from the fruit of Piper longum L. Phytotherapy Research, 23(8), 1194-1196. https://doi.org/10.1002/ptr.2630

18. Tikkanen M.J. (1996) Estrogens, progestins and lipid metabolism. Maturitas, 23, 51-55. https://doi. org/10.1016-/0378-5122(96)01012-2

19. Baigent C., Keech A., Kearney P.M., Blackwell L., Buck G., et al. (2005) Efficacy and safety of cholesterol-lowering treatment: Prospective metaanalysis of data from 90,056 participants in 14 randomised trialsofstatins. Lancet, 9493, 1267-1278. https://doi.org/10.1016/S0140-6736(05)67394-1

20. Liao K., Laufs U. (2005) Pleiotropic effects of statins. Annu. Rev. Pharmacol. Toxicol., 45, 89-118. https://doi.org/10.1146/annurev. pharmtox.45.120403.095748

21. Wagstaff R., Mitton W., McLendon B., Doraiswamy M. (2003) Statin-associated memory loss: Analysis of 60 case reports and review of the literature. Pharmacotherapy, 23(7), 871-880. https://doi. org/10.1592/phco.23.7.871.32720
22. Kromer A., Moosmann B. (2009) Statin-induced liver injury involves cross-talk between cholesterol and selenoprotein biosynthetic pathways. Molecular Pharmacology, 75(6), 1421-1429. https://doi.org/10.1124/mol.108.053678

23. Rao P., Kolla S., Elshaari F., Awamy H., Elfrady M., et al. (2015) Effect of piperine on liver function of CF-1 albino mice. Infect. Disord. Drug Targets, 15(2), 131-134. https://doi.org/10.2174/187152651 $\underline{5666150724114616}$

24. Piyachaturawat P., Glinsukon T., and Toskulkao C. (1983) Acute and subacute toxicity of piperine in mice, rats and hamsters. Toxicology Letters, 16(3-4), 351-359. https://doi.org/10.1016/03784274(83)90198-4

25. Wilkening S., Stahl F., Bader A. (2003) Comparison of primary human hepatocytes and hepatoma cell line HepG2 with regard to their biotransformation properties. Drug Metabolism and Disposition, 31(8), 1035-1042. https://doi.org/10.1124/dmd.31.8.1035

26. Smilkov K., Ackova D.G., Cvetkovski A., Ruskovska T., Vidovic B., et al. (2019) Piperine: Old spice and new nutraceutical? Curr. Pharm. Des., 25(15), 1729-1739, https://doi.org/10.2174/13816128256 $\underline{66190701150803}$

27. Thao D.T, Minh L.N, Anh T.T.M, Thi Nga N, Hue P.T.K, et al. (2021) The improved anticancer activities of piperine nanoliposome conjugated CD133 monoclonal antibody against NTERA-2 cancer stem cells. Natural Products Communications, 16(2), 1-7. https://doi. org/10.1177/1934578X21998184

28. Elnaggar S., Etman M., Abdelmonsif A., Abdallah Y. (2015) Intranasal piperine-loaded chitosan nanoparticles as brain-targeted therapy in Alzheimer's disease: Optimization, biological efficacy, and potential toxicity. J. Pharm. Sci., 104(10), 3544-56. https://doi.org/10.1002/ jps. 24557

29. Vig B.S., Huttunen K.M., Laine K., Rautio J. (2013) Amino acids as promoieties in prodrug design and development, Advanced Drug Delivery Reviews, 65(10), 1370-1385. https://doi.org/10.1016/j. addr.2012.10.001

30. Xu Q., Deng H., Li X., Quan Z.S. (2021) Application of amino acids in the structural modification of natural products: A review. Front. Chem., 9, https:// doi.org/10.3389/fchem.2021.650569 